sented by M.M. M. Stefanik, G. Millochau, and J. J. Landerer, who were in charge of the several instruments.

The results, which are of only a preliminary nature, are too numerous to give in detail here, but all the observations, both visual and photographic, appear to have been successful.

M. E. Stephan, of the Marseilles Observatory, was placed in charge of one of the expeditions organised by the Bureau des Longitudes, and, accompanied by M. Borrelly, occupied the same station as Mr. Newall, at Guelma (Algeria).

The equipment of this expedition consisted of a telescope of $40 \mathrm{~cm}$. aperture and an equatorial of $9.5 \mathrm{~cm}$. aperture and $190 \mathrm{~cm}$. focal length. A number of visual observations of the corona, the prominences, \&c., were successfully made.

Nova Aguile No. 2.-Circular No. 106 of the Harvard College Observatory describes the discovery and subsequent observations of Nova Aquilæ No. 2. The Nova was discovered on a plate taken with the $\mathrm{II}$-inch Draper telescope on August 18 for the Henry Draper memorial series. The spectrum, although faint, showed the lines $\mathrm{H} \delta, \mathrm{H} \gamma, 4272$, 4646 , and $\mathrm{H} \beta$ very broad and bright, $\mathrm{H} \gamma$ and $\mathrm{H} \beta$ having accompanying dark lines on their more refrangible edges. The helium line 4646 is slightly stronger than 4272 , and the whole spectrum closely resembles that of Nova Persei No. 2, as photographed on March 30, 1901.

Some two or three hundred plates of this region are included in the Harvard series, and twenty-nine of them, taken before August 18 , have been examincd, but no trace of the Nova before that date has been disccvered.

Two photographs showing the region half a degree square around the Nova, taken on August 15, 1903, and August 31 , 1905, respectively, are reproduced in the Circular, and on comparing them it is at once seen that the Nova does not appear on the former, although it is quite a conspicuous object on the latter plate; stars of magnitude 15.7 are shown on the earlier plate.

Prof. Pickering's tabulated statement of the observed magnitudes of the Nova from August 3I to September 22 shows that this object gradually decreased in brightness from magnitude $10.4 \mathrm{I}$ on the first named date to magnitude $x I .23$ on the second. When first photographed the Nova's magnitude was about $7 \cdot 0$.

It follows from the Harvard observations that the Nova first appeared between August 10 and August 18, but it is hoped that, when the plates taken at Arequipa during that period arrive at Cambridge (Mass.), this interval may be greatly reduced.

Star with a Large Proper Motion.-The method employed at Harvard College Observatory for the detection of variable stars, viz. the superposition of a photographic plate upon a glass positive of the same region, photographed on an earlier date, has led to the discovery that the star A.G.C. 6886 has a large proper motion. Whilst thus examining two plates of the Large Magellanic Cloud, taken on April I I, 1898, and December 5, 1904, respectively, Miss Leavitt found that this star had moved appreciably during the interval, and a comparison of the positions given in several of the older catalogues compiled since 1825 confirmed the fact.

The discussion of the data obtained from the comparison showed that the annual proper motion in R.A. is $-0.066 \mathrm{~s}$. in declination $+\mathrm{I}^{\prime \prime} \cdot 14$, and along a great circle $\mathrm{I}^{\prime \prime} \cdot 28$.

The total number of stars shown on the original negatives is about 300,000 , and it is probable that none of these, except A.G.C. 6886, has an annual proper motion exceeding three-quarters of a second (Harvard College Observatory Circular, No. Io5).

Observations of Perseids, August.-The detailed results of the Perseid observations, made at the meteorological observatory at Pavia on August 8, 9, 10, and II, are given in No. 8, vol. xxxiv., of the Memorie della Societó degli Spettroscopisti Italiani.

On the night of August 8-9 seven observers recorded ${ }_{153}$ meteors, and determined the trajectories of 23 of them. The maximum horary rate occurred between oh. and $\mathrm{rh}$. (August 9), during which time 53 meteors were seen. On the succeeding night the watch lasted from $22 \mathrm{~h}$. to $3 \mathrm{~h} .7 \mathrm{~m}$., NO. 1878 , vOI. 72$]$ and the same number of observers saw $25^{2}$ meteors, of which they recorded the paths of 28 . The maximum rate occurred during the last hour, when 93 meteors were seen. The third night produced 264 meteors, and of these the seven observers recorded the trajectories of 18 during their watch of $4 \mathrm{~h} .56 \mathrm{~m}$. The maximum horary rate of the whole shower, as observed at Pavia, was recorded during this watch, when 100 meteors were seen between $2 \mathrm{~h}$. and $3 \mathrm{~h}$. on the morning of August II.

Of the 669 meteors seen during the three nights, 27 were recorded as being brighter than, and 139 as being equal to, the first magnitude, whilst "swift" and "white" were the descriptive terms applied to the majority of them.

\section{MATHEMATICAL AND PHYSICAL SCIENCE AT THE BRITISH ASSOCIATION.}

THE great number of astronomers present during the South African meeting caused astronomy to play a larger part in the proceedings of the section than it has done in recent years, and many of the most important communications and discussions were on astronomical subjects. The number of papers on pure mathematics and on physics was relatively small.

Of the mathematical papers, one by Prof. Harzer on ancient Japanese mathematics was of special interest. Prof. Harzer finds on examining ancient Japanese records and works that several of the theorems discovered in Europe during the seventeenth century were known at least as early to Japanese mathematicians. As an example, the expansion

$$
(\arcsin y)^{2}=\sum_{0}^{\infty} \frac{\mathrm{I}}{\beta+\mathrm{I}} \cdot \frac{2 \cdot 4 \cdot 6 \ldots 2 \beta}{1 \cdot 3 \cdot 5 \cdots(2 \beta+1)} y^{2 \beta+2}
$$

due to Kowa Seki (1642-1708) may be quoted.

Mr. M. Cashmore showed how chess magic squares, i.e. squares of numbers which add up to the same amount along every path across the square in the direction of a rook's, a bishop's, or a knight's move, can be constructed by superposing on each other two types of subsidiary squares, which can be formed by simple rules.

Prof. Perry gave an account of the approximate method he had used to determine the stresses which occur in a winding rope carrying a cage when the upper end of the rope is suddenly stopped.

Mr. H. G. Fourcade described his instrument for stereoscopic surveying. It consists of a photographic camera which may be fixed in turn at the two ends of a base line with its axis perpendicular to that line. In front of, and close to, the sensitive plate a réseau scale on a glass plate is placed, and is reproduced on the two photographs taken.

The two are examined together in a measuring machine similar to that used in stellar photography, and by means of micrometer screws any portion of the picture may be made to appear in relief and coincident with an index. The distance of that portion from the base line may then be determined from the micrometer readings. Each determination takes about two minutes, and with a base of 300 metres the probable error does not exceed I part in Iooo for a distance of 10,000 metres, and is less for shorter distances.

Prof. Perry raised the question of the teaching of elementary mechanics, and pointed out that the average boy who enters a technical college is so badly educated that his first year has to be "wasted in the study of school subjects." Then three years are found to be insufficient to teach him " everything an engineer is likely to want in his profession," which many colleges foolishly attempt to do, and a fourth or even a fifth year is added. He urged that in teaching science to boys from nine to thirteen the methods of Mr. Barlow, of "Sandford and Merton" fame, should be followed, until they know something of levers, weighing and measuring, specific gravities, barometers and thermometers, and of electricity and magnetism. At the age of fourteen a boy should know elementary algebra and trigonometry, should be able to differentiate and integrate, and apply the calculus. The principles that if forces are in equilibrium their vector sum is zero, and the sum of their moments about any axis is 
zero, should be presented to him from many points of view. Force should be taken as the rate of change of momentum. All these facts should be brought out and illustrated by experiment, and it should be the object of the teacher to turn out a pupil with a thorough grasp of mechanical principles, and not one crammed with formulæ which he soon forgets.

With the report of the Mathematical Association committee on the teaching of mechanics Prof. Perry is substantially in accord, although he differs from it in wishing to retain the term "centrifugal force" and to abolish the "poundal.'"

Lord Kelvin communicated a paper on the kinetic and statistical equilibrium of ether in ponderable matter at any temperature. If two small spheres, one covered with black, the other with white cloth, were placed in space at the earth's distance from the sun, the temperature of the black sphere would be greater than that of the white. If the spheres were at a distance from the sun rooo times as great, and 999 other suns were scattered through space, all at about that distance from the spheres, the difference of temperature would be one-thousandth of the former difference. Dr. Chree has found, using thermometers, that in bright sunlight the difference of temperature is $1^{\circ} \mathrm{C}$. to $3^{\circ} \mathrm{C}$. On a starlight night we might therefore expect a difference of $0.001^{\circ} \mathrm{C}$. or $0.003^{\circ} \mathrm{C}$.

Dr. J. T. Bottomley described his experiments on the cooling of a lamp-blacked or silvered copper sphere in an evacuated spherical copper enclosure kept first at the temperature of liquid air, then, when the sphere has cooled, raised to the temperature of boiling water. Temperatures were observed thermoelectrically. The present results agree with those found previously by Dr. Bottomley, and do not support Stefan's law.

The writer reviewed the recent experimental work on the thermal conductivities of substances, and pointed out that the balance of evidence is in favour of many substances decreasing in thermal conductivity as their temperature is raised.

Mr. A. Word gave a résumé of the work done during the past year in the Cavendish Laboratory and elsewhere which justifies the conclusion that all substances are more or less radio-active.

Prof. Beattie described his observations on atmospheric electricity in South Africa, and his attempt to connect the observed conductivity of the air with other meteorological phenomena, an attempt which he considered had proved unsuccessful.

Communications on the meteorology of South Africa by Dr. Mill and by Mr. R. F. Rendall were read, and Prof. Beattie gave an account of the present state of the magnetic survey of the country, and exhibited charts embodying the results for the declination. Necessarily the work has had to be confined to positions near the railways, and it will be necessary to provide some means of extending the field of operations, especially along the western coast of South Africa. The association made a grant of rool. towards the expense of this extension.

Great interest was shown in Sir David Gill's account of the geodetic survey in South Africa and the African arc of meridian. After the completion of the survey of Cape Colony and Natal in 1892 , it became necessary to determine with greater accuracy the position of the twentieth parallel of longitude north of the colony at points where it formed the boundary of British and German territory. The work was placed in Sir David Gill's hands by the two Governments, and completed in 1903. At the same time, under the auspices of the Rhodesian Government, surveys of northern and southern Rhodesia were being carried out, partly in connection with the AngloPortuguese boundary. Since the war, surveys of the Transvaal and Orange River Colony have made steady progress, and the results so far obtained were embodied in the chart of South Africa exhibited by Sir David Gill. Throughout the work the bases taken were measured with the help of wires which were compared with a standard base 400 feet long before and after use. The discordance in the measurements of the $\mathrm{Gwibi}$ base of about 70,000 feet amounted in the aggregate to $I$ part in $I \cdot 5$ millions, and this was the base measured with least accuracy.

As a result, it appears that along the meridian of $19^{\circ}$ Nก. 1878 , vOL. 72$]$ east longitude the curvature of the earth agrees with that given by Clarke's elements, but along meridian $26^{\circ}$ east, and more markedly along meridian $30^{\circ}$, this appears not to be the case. A definite settlement of the question will only be possible after the connection of the Rhodesian triangulation with that of the rest of South Africa, a connection which will entail a cost of about $1600 l$. When this has been achieved, Sir David Gill will have made one step more towards the carrying out of his scheme for a great African arc of meridian extending from the Cape to Cairo, and by combination with the Russian-Scandinavian arc, a great arc from the Cape of Good Hope to the North Cape. The scheme has the hearty approval of Section. A.

It is somewhat remarkable that at Cape Town the section should hear an account of a geodetic survey. of a country within the Arctic circle, but the details of the geodetic survey of Spitsbergen given by its director, $\mathrm{Dr}$. O. Backlund, proved of great interest. It was undertaken by the Swedish and Russian Governments, was carried out on the same lines as that in South Africa, and has given results of a high order of accuracy considering the difficulties of work in such a country. The values of 8 found at some of the stations in the mountainous parts of the country come out in defect by two or three figures in the fourth place.

One of the most important communications to the section was that of Prof. Kapteyn on star streaming. Prof. Kapteyn finds that the stars, the proper motions of which relative to the solar system have been determined, fall into two groups, one in which the motions take place in the main parallel to a line joining the sun to a point $7^{\circ}$ south of $\alpha$ Orionis, the other with its motions parallel to the line joining the sun to a point $2^{\circ}$ south of $\eta$ Sagittarii. If the motions of these two streams be referred to the centre of gravity of the whole of the stars considered, their directions must be diametrically opposite. One of the vertices of these motions in opposite directions Kapteyn finds is close to $\xi$ Orionis, and both lie in the central line of the Milky Way. Prof. Kapteyn does not hold that all motions must be in this line, but that there is a great preponderance of such motions, and that motions oblique to it get fewer the greater the obliquity. At this stage of the investigation he wishes to stand until further knowledge of the motions of stars in the line of sight has been obtained spectroscopically.

Dr. A. W. Roberts gave an account of the observations he has made during the past five years on the light fluctuations of certain southern binary stars, especially V. Puppis. $\mathrm{He}$ has succeeded in reaching a high degree of accuracy, and has determined the orbital elements of six stars by means of his observations, using the relations given by Rambaut. He finds the masses of two of the six systems to be 60 to 300 times, and the densities 0.00002 to 0.36 time, those of the sun. The large masses are somewhat exceptional, and $\mathrm{Mr}$. Jeans suggested that the light curves of stars of pear shape would be found to agree with the observations made by Roberts. In support of this, Mr. Jeans gave an account of his investigation of the condensation of a gas occupying initially the whole of space about centres at distances apart approximately equal to that from the solar system to the nearer stars, and with the mass at each centre of the same order as that of the sun. Any one of these nuclei might take a spheroidal, ellipsoidal, or a pear shape, or separate into two parts, according to its velocity of revolution.

$\mathrm{Mr}$. R. T. A. Innes gave an account of the state of double star astronomy in the southern hemisphere, and pointed out the importance of bringing up the observations in the southern to the same state as those in the northern hemisphere. He considers the position and climate of Johannesburg offer exceptional opportunities for the work, and suggested the provision of a telescope by the Transvaal Government. Sir David Gill supported this suggestion.

Of shorter communications it is only necessary to mention a few, e.g. Prof. E. W. Brown's on the present state of lunar theory and the necessity of a new set of lunar tables, and Dr. Rambaut's on a new instrument for measuring stellar photographs, to show that in interest and importance the sectional work in South Africa in no way falls behind that of the meetings at home.

C. H. LEes. 